\title{
Operation Principle and Topology Structures of Axial Flux- Switching Hybrid Excitation Synchronous Machine
}

\author{
Xiping Liu*, Chen Wang**, Aihua Zheng***
}

\begin{abstract}
The operation principle of an axial flux-switching hybrid excitation synchronous machine (AFHESM) is analyzed and its topology structures are proposed in this paper. After some comprehensive analysis of the operation principle to axial flux electrical machine, fluxswitching electrical machine and hybrid excitation electrical machine, the operation principle of AFHESM is given. Combined with some typical topological structures of hybrid excitation electrical machine, some possible topological structures are proposed and some comprehensive comparisons are carried out. The analysis results show that the statorseparated AFHESM has some advantages such as less AM turns, less impact on the demagnetization of PM, less magnetic flux-leakage and higher efficiency compared to other topologies.
\end{abstract}

Keywords: Hybrid excitation, Flux-switching, Topology structure, Axial flux, Operation principle.

\section{Introduction}

Flux-switching permanent magnet machine (FSPM) is a simple structure machine due to PMs installed in its stator [1],[2], and no PMs or windings on the rotor. The magnetic flux path can be switched automatically and the flux linkage in stator winding is varied with its rotor position changed, which results in an alternating induced EMF in the stator winding. This type of machine has some advantages such as small size, light weight, reliable working performance, higher power density and efficiency and so on.

Hybrid excitation synchronous machine (HESM) has recently been the subject of extensive research since it combines the advantages of PM electrical machines with the possibility of controlling air-gap magnetic flux easily by auxiliary windings.. It is well suited to constant generation and constant power operation with a wide range of speed applications. In recent years, many topologies of HESM have been proposed and a series of achievements have been obtained, such as consequent pole PM machine (CPPM) [3], claw-pole type rotor [4], combination rotor type [5], parallel structure type [6], separate magnetic circuit [7], etc.

With a rapid development of wind power, oil exploitation, automobile, elevators drive and other industries, the

\footnotetext{
* Dept. of Electrical Engineering and Automation, Jiangxi University of Science and Technology, China. (liuxp211@163.com).

Received 10 March 2012; Accepted 26 July 2012
}

electrical machine with a higher efficiency and lower speed are needed in many cases. Compared with the traditional radial flux electrical machine, the axial flux electrical machine has more advantages such as the higher efficiency rotor core (more than 95\%), well heat dissipation, shorter axial stator core, more compact structure, lighter weight, smaller volume, etc. To meet the need of low work speed, the more pole pairs can be designed for the axial flux electrical machine, and the bigger starting torque and higher power density [8],[9] can also be obtained. The further research and development on axial flux electrical machine are carried out by some research institutes and rich research achievements of theory and application are acquired. For example, a coreless generator for automotive applications [10], wind generator [11]-[16], motor for wheel direct drive [17],[18], motor for direct-drive elevator systems [19], motor for ship propulsion drives [20], etc. Some prototype machine were successfully developed, such as a coreless axial flux generator with the rated speed of 1000r/min [10], a $1.6 \mathrm{~kW}$ axial flux PM wind generators with concentrated winding [14], a small wheel motor for electric passenger cars with $185 \mathrm{r} / \mathrm{min}$ and $4.1 \mathrm{~kW}$ [18], a double rotor axial flux PM motor with the rated speed of $95 \mathrm{r} / \mathrm{min}$ and $5 \mathrm{~kW}$ for direct-drive elevator [19], a small double rotor PM motor for ship propulsion drives [20], the double rotor coreless disc PM synchronous machine with Halbach array [21], axial flux-switching PMSM [22], wheel disc PMSM [23], novel disc PMSM for pumping unit [24], disc PM synchronous generator [25] and so on. 
In order to combine the advantages of flux-switching PM machine and axial flux PM machine, and obtain a good field control ability, an axial flux-switching hybrid excitation synchronous machine (AFHESM) is proposed in this paper. The operation principles of this machine are analyzed, and some useful topologies are given in the paper.

\section{Operational principle of AFHESM}

An AFHESM is composed of stator and rotor part. The stator mainly includes " $\mathrm{H}$ " type stator core, $\mathrm{PMs}$, armature windings and field windings, etc. Several stator cores assembly form the whole stator core of AFHESM. Some alternately magnetized PMs are embedded in the adjacent stator cores. The concentrated armature windings are embedded in the adjacent stator cores separated by PMs. The field windings are axially winded on the surface of PMs. In order to overcome the unilateral magnetic pull, the dual-rotor structure is adopted in AFHESG. The two rotors symmetrically distributed are coaxially connected with the stator, and fixed on the cover of machine through the bearings. The rotor of AFHESG is composed of rotor teeth and rotor yoke, and the rotor teeth are radically distributed on the surface of rotor yoke. For the machine, the stator core and rotor are piled up by winding-type silicon steels.

The magnetic field is mainly created by PM MMF when no field current is applied. According to the principle of the least reluctance for magnetic circuit, the machine works in the flux switching state, and most of magnetic flux passes through N pole of PM, "H" type stator core, air-gap, rotor tooth, rotor yoke, adjacent rotor tooth, air-gap, adjacent " $\mathrm{H}$ " type stator core, and S pole of PM. From the angle of magnetic circuit, the magnetic circuit of AFHESM varies for a period when it rotates from one " $\mathrm{H}$ " type unit stator core to the adjacent one. At this time, the magnetic flux in armature winding also varies for one period, that is, the magnetic flux goes into and pierces out of armature winding, as shown in Fig. 1(a) and (b) respectively. Thus, the induced EMF of armature also varies for one period, as shown in Fig. 1(c).

When a DC field current is applied, the magnetic flux path is the same as the PMs work alone. The resultant airgap magnetic field is strengthened when a positive current is injected to field winding, so that the flux linkage in the armature windings is increased, and the EMF is also increased accordingly. On the contrary, the resultant air-gap magnetic field can be weakened with a opposite direction of the field current applied, at the same time, the flux linkage and EMF in armature windings is also be decreased accordingly ture windings is also be decreased accordingly.

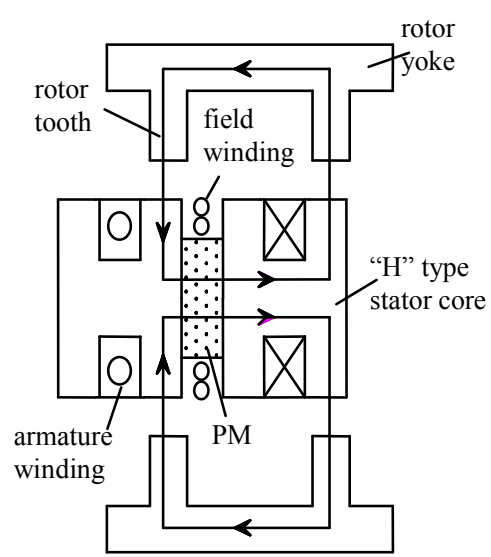

(a)

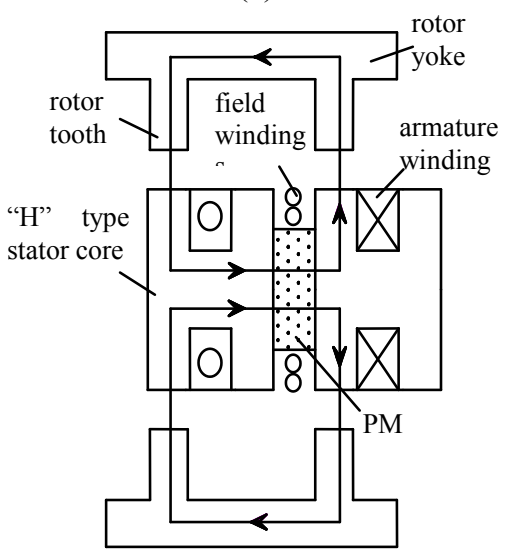

(b)

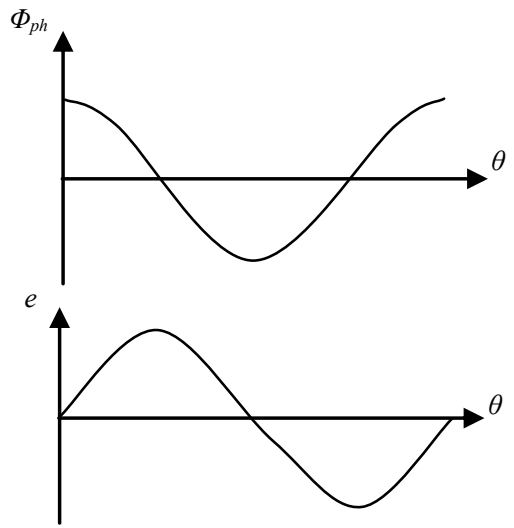

(c)

Fig.1. Flux-switch principles of AFHESM. (a) Flux into the windings. (b) Flux piercing out windings (c) Coil flux /induced EMF

\section{Topology Structure of AFHESM}

The structure of the flux-switching PM electrical machine will be changed as a field winding is added. Based on the deep analysis of machines that PMs on the stator such as doubly-salient PM machine and flux-reversal 
machine, the design ideas of the machines such as hybrid excitation claw pole machine, hybrid excitation switched reluctance machine, hybrid excitation brushless DC machine, hybrid excitation linear synchronous machine, hybrid excitation doubly-salient machine, etc. and combined with the technology developments on PM materials and core soft magnetic material, some rational structures of AFHESM are found. In the following, several topology structures of AFHESM are proposed according to the combination of stator and rotor and layout of field winding.

\subsection{Classified by the Combination of Stator and Rotor}

\subsubsection{Single Stator and Single Rotor}

The scheme of AFHESM with single stator and single rotor is shown in Fig. 2 and its structure model is shown in Fig. 2(a). The stator mainly consists of "U" type unit stator core, PMs, field windings, armature windings and so on, the PMs alternately magnetized are embedded in the two adjacent stator cores. A field winding is axially winded on surface of PMs and some armature windings circumferentially cross the adjacent " $U$ " type stator core teeth. The rotor is mainly composed of rotor teeth and rotor yoke, and the rotor teeth are evenly distributed on the surface of rotor yoke. Fig. 2(b) shows the magnetic circuit, which mainly consists of $\mathrm{N}$ pole of PM, unit stator core yoke, unit stator core tooth, air-gap, rotor tooth, rotor yoke, rotor tooth, air-gap, adjacent unit stator core tooth, adjacent unit stator core yoke and S pole of PM. Fig. (c) gives its simplified magnetic circuit, where $F_{p m}$ represents PM potential, $F_{e}$ is excitation magnetic potential, $R_{p m}$ is $P M$ reluctance, $R_{\text {sy } 1}$ is unit stator core yoke reluctance, $R_{\text {st1 }}$ is unit stator core tooth reluctance, $R_{\text {sy } 2}$ is adjacent stator core yoke reluctance, $R_{\text {st2 }}$ is adjacent stator core teeth reluctance, $\mathrm{R}_{\delta 1}$ and $\mathrm{R}_{\delta 2}$ represent air gap reluctance, $\mathrm{R}_{\mathrm{rt} 1}$ is rotor tooth reluctance, $R_{r t 2}$ is adjacent rotor tooth reluctance, $R_{r y}$ is rotor yoke reluctance and $\Phi_{\delta}$ is air-gap flux.

When the machine works, the main air-gap flux is produced by PMs, and the air-gap magnetic field can be adjusted easily by changing the magnitude and direction of field current. Although its structure is simple due to one rotor and one stator, there is unilateral magnetic force when the machine works, which easily leads to mechanical vibrations and affect its normal operation. Further more, there are demagnetization risks for the PMs in machine.

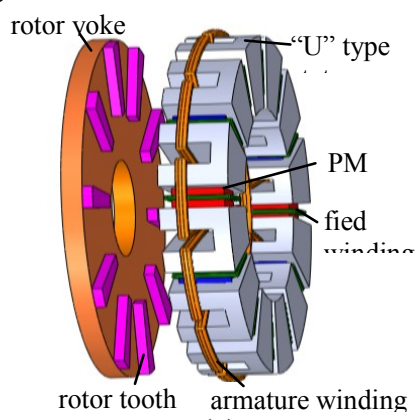

(a)

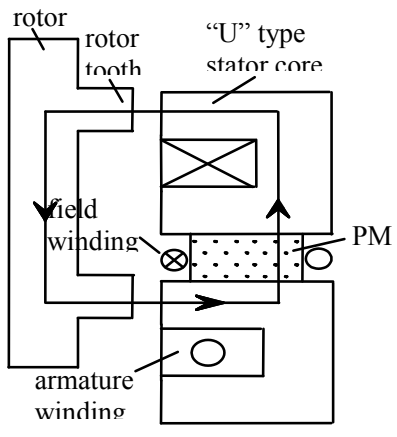

(b)

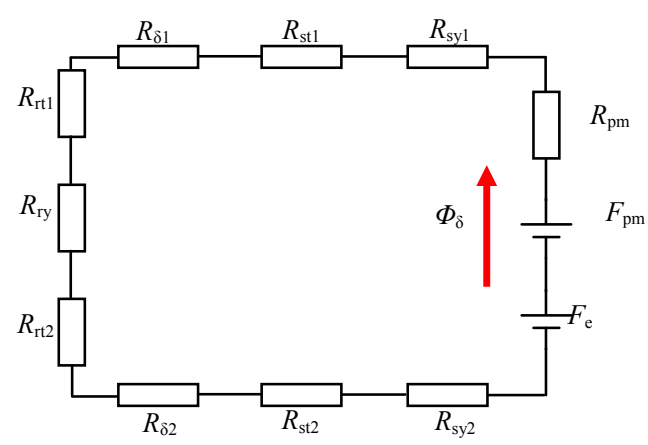

(c)

Fig.2. Structure with single stator and single rotor. (a) Structure. (b) Flux path. (c) Simplified magnetic circuit

\subsubsection{Structure with Single Stator and Double Rotor}

The scheme of AFHESM with single stator and double rotors is shown in Fig. 3 and its structure model is shown in Fig. 3(a). The stator mainly includes "H" type stator core, PMs, field windings and armature windings, etc. Some PMs that staggered magnetization are embedded in the two adjacent stator cores. The field windings are axially winded on the surface of PMs and the concentrated armature windings embed in the adjacent stator core separated by PMs. The rotor of machine is mainly composed of rotor teeth and rotor yoke, and the rotor teeth are evenly distributed on the surface of rotor yoke. Fig. 3(b) shows 
that the magnetic circuit of machine, which is composed of two completely symmetrical parts, and each part is the same as AFHESM with single rotor and single stator. The unilateral magnetic force of the machine can be overcome due to the two symmetrical rotors, but there are demagnetization risks for the PMs too.

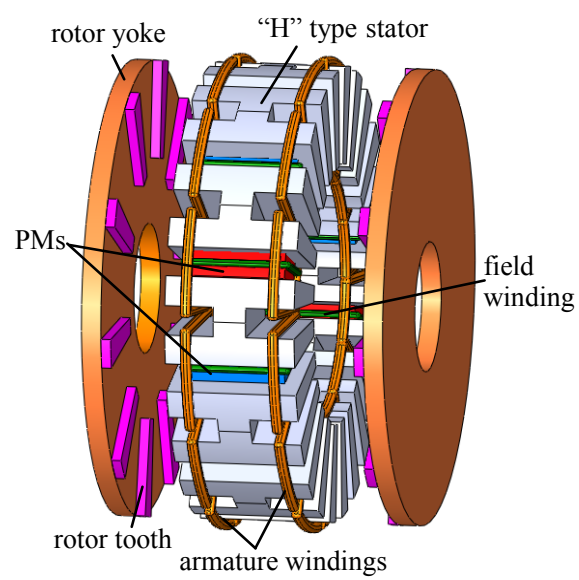

(a)

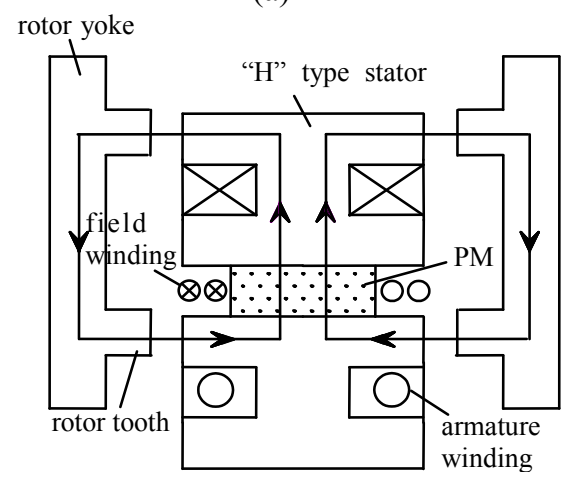

(b)

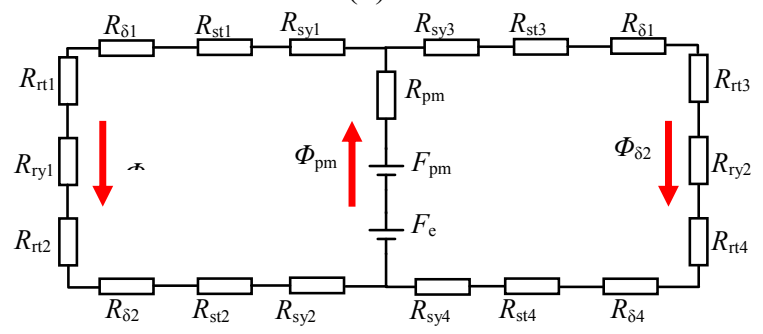

(c)

Fig.3. Structure with single stator and double rotors. (a) Structure. (b) Flux path. (c) Simplified magnetic circuit

\subsubsection{Structure with Double Stator and Single Rotor}

There are two types of AFHESM with double stators and one rotor, which are shown in Fig. 4 and Fig. 5 respectively. One type of the machine is the corresponding PMs on both sides of the stator with the same magnetization direction, and its structure model is shown in Fig. 4(a). Two stators are symmetrically distributed on both sides of rotor, and the stator is the same as the stator in Fig. 1(a). The rotor is mainly composed of rotor teeth and rotor yoke, and the rotor teeth are evenly distributed on the inner and outer surfaces of rotor yoke. As the same magnetization direction of the corresponding PMs on both sides of the stator, the magnetic circuit is consisted of two completely symmetrical parts, and each part is the same as AFHESM with single rotor and single stator, as shown in Fig. 4(b). The simplified magnetic circuit of the machine (half of the machine model) is shown in Fig. 4(c). When the machine works, it can be seen as two parts that work independently. The unilateral magnetic force can be overcome due to the two symmetrical rotors. The two stators are completely symmetrically distributed on both sides of the rotor, so the installation is complex.

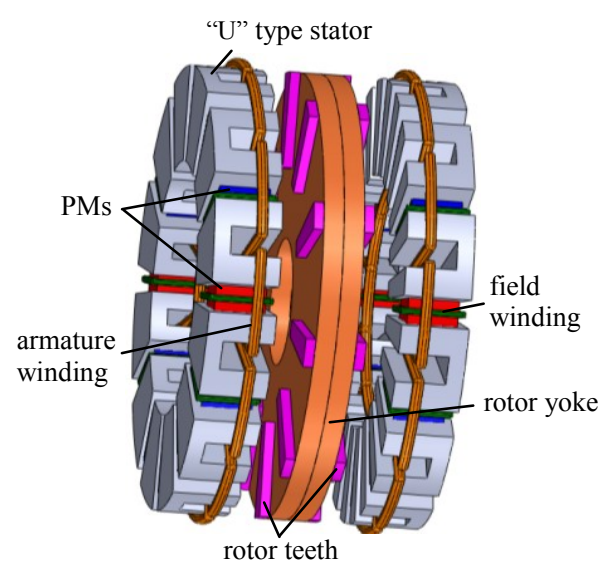

(a)

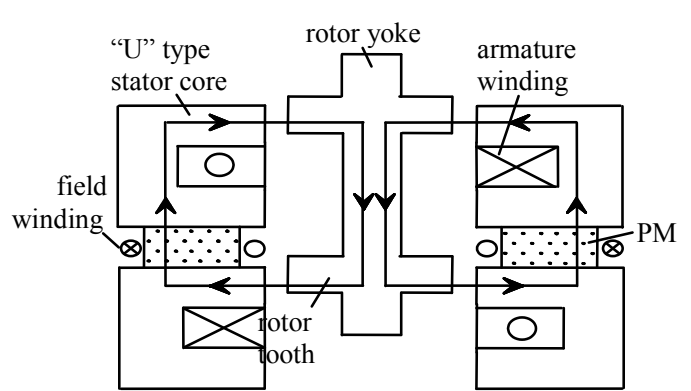

(b)

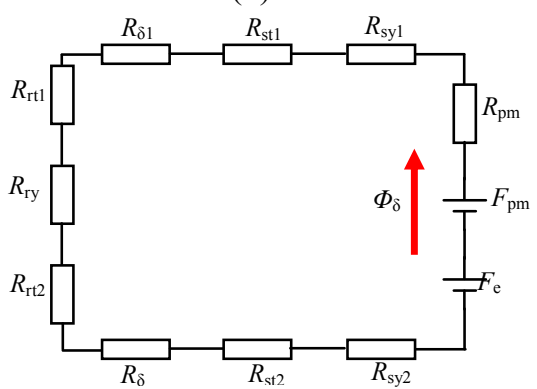

(c)

Fig.4. Structure with double stators and single rotor. (The corresponding PMs have the same magnetization direction). (a) Structure. (b) Flux path. (c) 
Simplified magnetic circuit

The other type of the machine is the corresponding PMs on both sides of the stator with an opposite magnetization direction shown in Fig. 5. Fig. 5(a) gives its structure model, and it can be found that the rotor is different compared with Fig. 4,. The machine rotor is mainly composed of rotor teeth and rotor yoke, and the rotor teeth are distributed evenly on the outer surface of rotor yoke made in nonmagnetic material. Due to the opposite magnetization direction for PMs on both sides of the stator, the left and right magnetic circuits are in series, of which the simplified magnetic circuit is shown in Fig. 5(c). The unilateral magnetic force can also be overcame due to the two symmetrical rotors. Compared to the structure shown in Fig. 3 , the axial length of the rotor and rotational inertia can be reduced when the magnetic circuits of machine are in series. The two stators are distributed completely symmetrically on both sides of the rotor, so the installation is more complex.

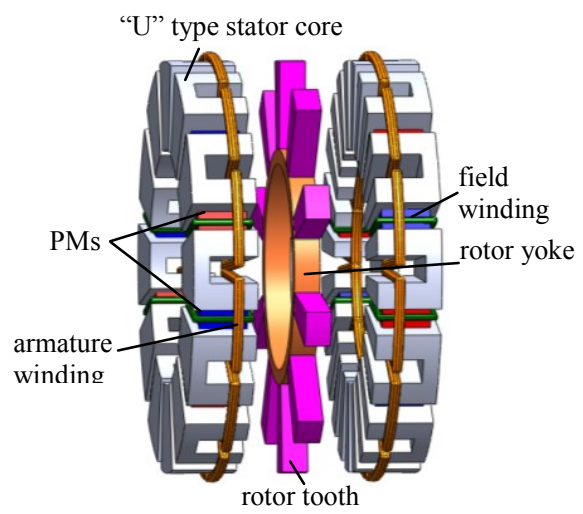

(a)

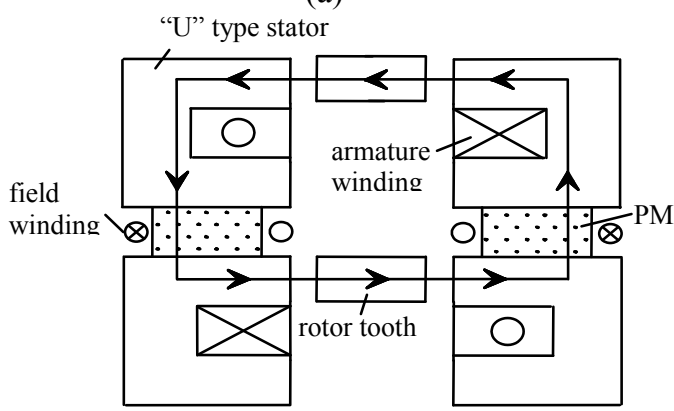

(b)

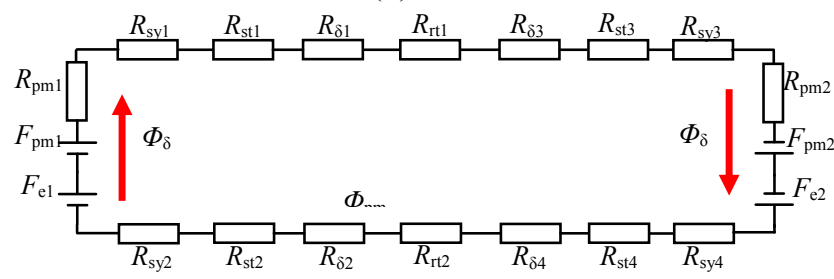

(c)

Fig.5. Structure with double stators and single rotor. (The corresponding PMs have the opposite magnetization direction). (a) Structure. (b) Flux path. (c) Simplified magnetic circuit

3.1.4 Structure with Multistage Stator and Rotor

Fig. 6 shows the scheme of AFHESM with multistage stator and rotor, and the structure with two-stage stator and rotor is given in the diagram. The structure, magnetic flux path and simplified magnetic circuit are shown in Figs. 6(a) (b) and (c) respectively. This type of machine can enhance the output voltage as a generator or the starting torque as a motor. Its volume is larger, so it is limited by the installation space.

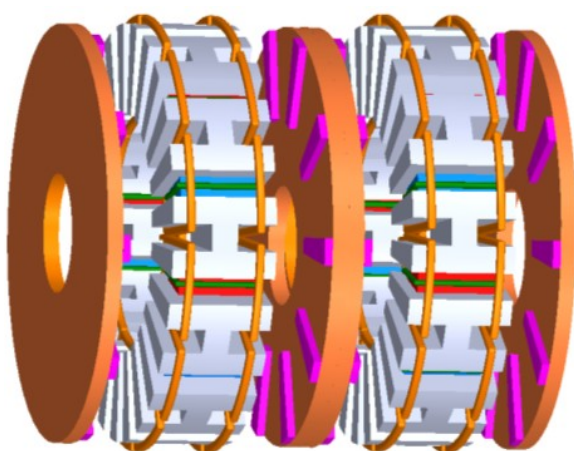

(a)

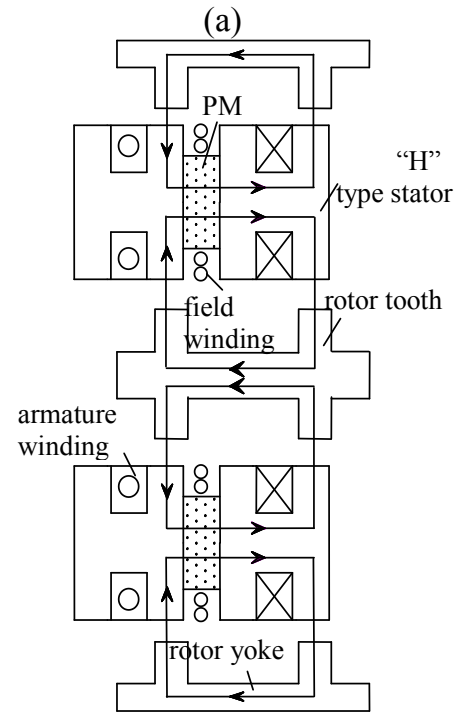

(b)

Fig.6. Structure with multistage stator and rotor. (a)

Structure. (b) Flux path

\subsection{Classified by the Layout of Field Winding}

\subsubsection{Field Windings are Winded on the PMs Directly}

Fig. 7 shows the structure of AFHESM that the field windings are winded on the PMs directly. When it works, the heat generated by the field current will rise the temperature of PMs. Thus, some demagnetization risks can be occurred for PMs and the PMs are not stable during 
working. In addition, more AM turns are needed to produce certain electrical excitation flux since the PM reluctance, which will increases the excitation loss and heat and reduces the machine efficiency.

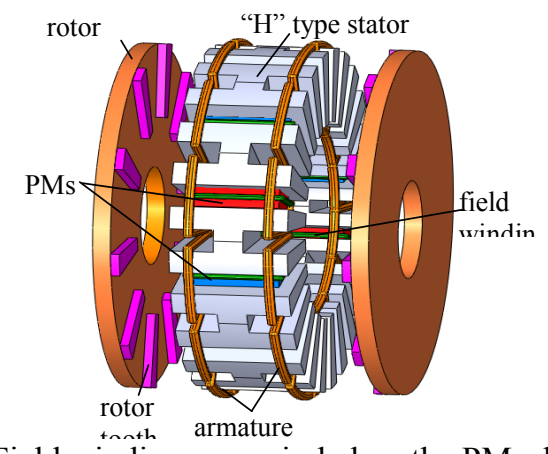

Fig.7. Field windings are winded on the PMs directly

\subsubsection{Field Windings are Separated from the PMs}

Fig. 8 gives the typical structure of AFHESM that field windings are separated from the PMs. The PMs and field windings are placed in the space of the two adjacent unit stator cores in parallel. The field windings are winded on the field brackets, which form a whole with the stator cores. This type of machine can avoid the demagnetization risks to some extent, however, a part of the PM flux may become leakage flux through field brackets, so the machine power density will be reduced.

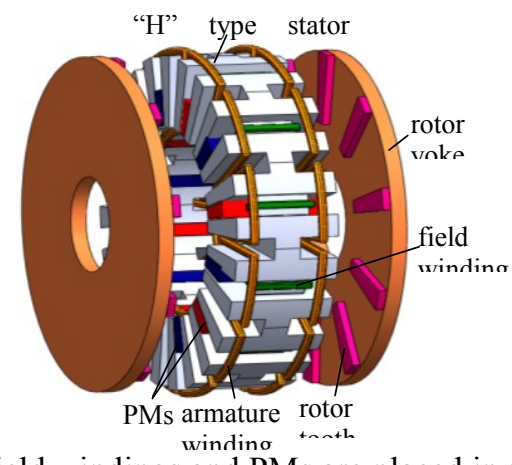

Fig.8. Field windings and PMs are placed in parallel

\subsection{Classified by the Relationship of PM MMF and Elect rical Excitation MMF}

3.3.1 PM MMF and electric excitation MMF are in series

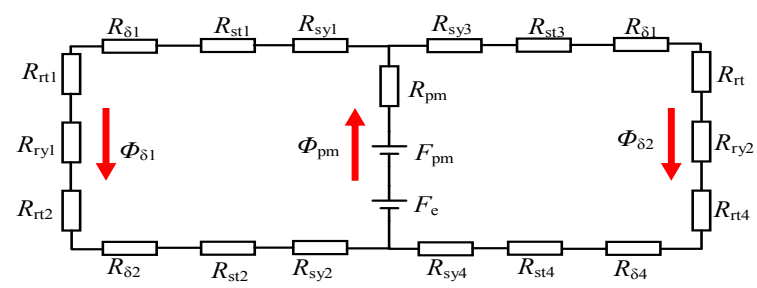

Fig.9. PM MMF and electric excitation MMF are in series

Fig. 9 is the typical magnetic circuit when PM MMF Fpm is in series with the electric excitation MMF Fe. The two MMFs have the same magnetic circuit, and the main flux is produced by PM MMF and the flux that regulating the air-gap magnetic field is produced by electric excitation MMF. The larger PM reluctance in the magnetic circuit, $s$ more AM turns are needed to produce certain flux, which increases the field winding reluctance and heat, and affect the working effect of PMs.

\subsubsection{PM MMF and excitation MMF are in parallel partly}

To avoid the demagnetization risks of PMs, PM magnetic circuit and field excitation magnetic circuit should be designed in parallel. Fig. 10 shows a typical magnetic circuit of AFHESM that PM MMF and excitation MMF are in series partly when a field current is applied. This type of machine can avoid the PM demagnetization risks, however, a part of PM flux may be shorted and became leakage flux through field bracket, so the power density of the machine will be reduced.

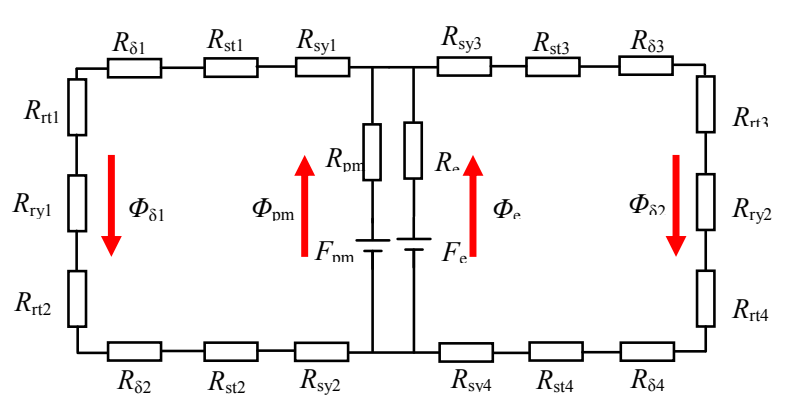

Fig.10. $P M M M F$ and excitation MMF are in parallel partly

\subsubsection{PM MMF and excitation MMF are in parallel totally}

To avoid leakage flux above mentioned, PM magnetic circuit and field excitation magnetic circuit should be designed in parallel completely and the structure and magnetic circuit of a typical AFHESM are shown in Fig. 11(a) and Fig. 11(b) respectively. The parallel PM and field winding are placed in the middle of two adjacent unit stator cores. The field windings are winded on the field brackets, and the stator core is divided into two independent parts by the non-magnetizer. This type of machine can not only avoid the PM demagnetization risks, but also prevent the PM flux form shorted through field bracket. It has some advantages such as simple structure, higher reliability, 
power density, etc.

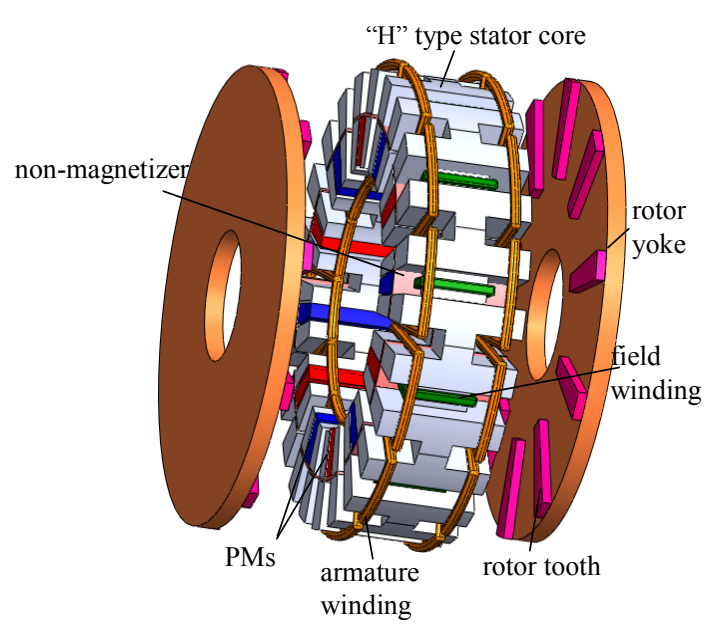

(a)

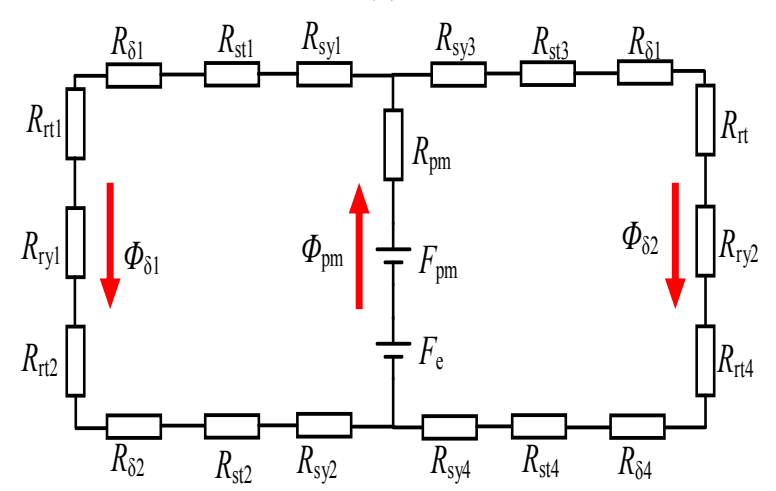

(b)

Fig.11. PM MMF and excitation MMF are in parallel totally . (a) Typical structure model. (b) Typical magnetic circuit

\section{Comprehensive Comparisons of Topology Structures}

For obtaining the same field control ability, some comparisons to above mentioned topologies in series, in parallel and independent topological structures of AFHESM under the same volume are given in table 1, which shows the qualitative analysis in aspects of AM turns, the impact on the demagnetization of PM, the size of the magnetic flux-leakage, efficiency manufacturing processes and so on. From the analysis it can be seen that the topology with an independent magnetic circuit has some advantages such as less AM turns, less impact on the demagnetization of PMs, less magnetic flux-leakage and higher efficiency compared to other topologies. However, the manufacturing process is relatively complicated, but it can be completely overcome due to the advanced automation and mechanical manufacture level.
Table 1. Comparisons of AFHESM topologies

\begin{tabular}{|c|c|c|c|}
\hline PMF & in series & In parall & in dependent \\
\hline AM turns & more & little & less \\
\hline $\begin{array}{c}\text { Demagnetization of } \\
\text { PMs }\end{array}$ & largest & large & less \\
\hline $\begin{array}{c}\text { Magnetic flux- } \\
\text { leakage }\end{array}$ & large & largest & less \\
\hline Efficiency & lower & higher & highest \\
\hline $\begin{array}{c}\text { Manufacturing } \\
\text { process }\end{array}$ & simple & complex & complex \\
\hline
\end{tabular}

\section{Conclusion}

For obtaining the same field control ability, some comparisons to the above mentioned topologies under the same machine volume are given in Table 1, which shows that the topology with a independent magnetic circuit has some advantages such as the less AM turns, the less impact on the demagnetization of PMs, the less magnetic flux leakage and the higher efficiency compared to other topologies.

\section{Acknowledgements}

This work was supported by the National Natural Science Foundation of P. R. China (No.51007033), and the Plan Project of Jiangxi Province of P. R. China (GJJ09517).

\section{References}

[1] Y. Chen and Z. Q. Zhu, "Three-Dimensional lumpedparameter magnetic circuit analysis of single-phase fluxSwitching permanent-magnet motor",IEEE Transactions on Industry Applications, vol. 44, no.6,pp. 1701-1710, Nov/Dec. 2008.

[2] Y. Cheng, C. Pollock and H. A. Pollock, "Permanent magnet flux switching motor for low energy axial fans,"40th IAS Annual Meeting, Oct. 2-6, 2005, pp. 2168-2175.

[3] J. A. Tapia, F. Leonardi and T. A. Lipo, "Consequent pole permanent magnet machine with extended field weakening capability," IEEE Trans on Industry Applications, Vol. 39, No. 6, 2003,1704-1709.

[4] Wang Qunjing, Li guoli and Ma Fei, "Electromagnetic analysis at no load and inductance calculation of the hybrid claw PM generator," Transactions of China Electrotechnical Society, 2002, 17(5): 1-5.

[5] M. Kotaro, F. Tadashi and N. Nobuyuki, "Performance prediction of a Hybrid-excitation synchronous machine with axially arranged excitation poles and Permanent-magnet poles," Electrical Engineering in Japan, Vol. 150, No. 2, 2003 , 43-49.

[6] Yan Yangguang and Chen zhihui, "Hybrid excitation synchronous motor," China, 200310106347[P]. 2004.11.10 
[7] Z. R. Zhang, Y. G. Yan, S. S. Yang and B. Zhou, "Principle of operation and feature investigation of a new topology of hybrid excitation synchronous machine," IEEE Trans on Magnetics, Vol. 44, No. 9, 2008: 2174-2180.

[8] A. Parviainen, M. Niemelä, J. Pyrhönen and L. J. Mantere, "Performance comparison between low-speed Axial-flux and Radial-flux permanent magnet machines including mechanical constraints," IEEE International Electric Machines \& Drives Conference May. 15-18, 2005, pp. 16951702.

[9] R. Qu, M. Aydin and T. A. Lipo, "Performance comparison of Dual-rotor Radial-flux and Axial-flux permanent-magnet BLDC machines," IEEE International Electric Machines \& Drives Conference, Jun. 1-4, 2003, pp. 1948-1954.

[10] Y. P. Yang and D. S. Chuang, "Optimal design and control of a wheel motor for electric passenger cars," IEEE Transactions on Magnetics, vol. 43, no. 1, pp. 51-61, Jan. 2007.

[11] Y. Chen, P. Pillay and A. Khan, "PM wind generator comparison of different topologies," 39th IAS Annual Meeti, Oct. 3-7, 2004, pp. 1405-1412.

[12] E. Spooner and A. Williamson. Modular, "Permanent-magnet wind turbine generators," 31th IAS Annual Meeting, Oct. 610, 1996, pp. 497-502.

[13] S. Brisset, D. Vizireanu and P. Brochet, "Design and optimization of a Nine-phase Axial-flux PM synchronous generator with concentrated winding for Direct-drive wind turbine," IEEE Transactions on Industry Applications, vol. 44, no. 3, pp. 707-715, May/Jun. 2008.

[14] A. Parviainen, J. Pyrhönen and P. Kontkanen, “Axial flux permanent magnet generator with concentrated winding for small wind power applications," IEEE International Electric Machines \& Drives Conference May, 15-18, 2005, pp. 11871191.

[15] T. F. Chan and L. L. Lai, "An Axial-flux permanent-magnet synchronous generator for a Direct-coupled Wind-turbine system," IEEE Transactions on Energy Conversion, vol. 22, no. 1, pp. 86-94, Mar. 2007.

[16] M. Andriollo, M. D. Bortoli, G. Martinelli, A. Morini and A. Tort, "Permanent magnet axial flux disc generator for small wind turbines," IEEE International Conference on Electrical Machines, Sep, 6-9, 2008, pp. 1045-1050.

[17] F. Carrichi, F.Crescimbini and F. Mezzetti, "Multistage axialflux PM machine for wheel direct drive," IEEE Transactions on Industry Applications, vol. 32, no. 4, pp. 882-887, Jul/Aug. 1996.

[18] S. Javadi and M. Mirsalim, "A coreless Axial-flux Permanent-magnet generator for automotive applications," IEEE Transactions on Magnetics, vol. 44, no. 12, pp. 45914598, Dec. 2008.

[19] R. Ficheux and F. Caricchi, "Axial-flux Permanent-magnet motor for direct-drive elevator systems without machine room," IEEE Transactions on Industry Applications, vol. 37, no. 6, pp. 1693-1701, Nov/Dec. 2001.

[20] F. Caricchi, F. Crescimbini and O. Honprati, "Modular axial flux permanent motor for ship propulsion drives," IEEE Transactions on Energy Conversion, vol. 14, no. 3, pp. 673 679, Sep. 1999.

[21] Wang Xiaoyuan, Tang Renyuan, Du Jingjuan, Zhao Fang and Qi Lixiao, "The optimal design of disc coreless PM synchronous motor based on the Halbach Array -Wedge Airgap structure motor," Transactions of China Electrotechnical Society, 2007, 22(3):1-5.
[22] Lin Mingyao, Zhang Lei and Li Xin, "Cogging torque analysis of axial magnetic flux switching permanent magnet motor," Electric Machines and Control, 2009, 13(5): 787-791.

[23] Huang Surong, "The design technology of modern disc wheel motor," Electrical Machinery Technology, 2005, (3):3-7.

[24] Lu Qinfen, Fan chengzhi and Yeyunyue, "The magnetic field and force characteristics of new pumping unit," Journal of zhejiang university (engineering version),2008, 42(4):651655.

[25]Huang Keyuan, Ou Jinsheng, Huang shoudao and Gao Jian, "The electromagnetic analysis of disc PM synchronous generator," Journal of hunan university (science version), 2008, 35(3):41-45.

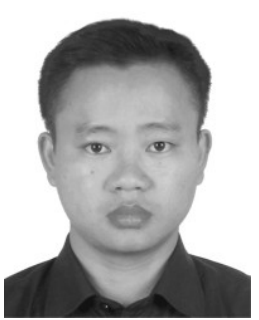

Xiping Liu received the B.S. degree from Hohai University, Nanjing, China, in 1999, and the M.S. degree from Jiangxi University of Science and Technology, Ganzhou, China, in 2004, and his Ph.D. degree in electrical engineering from Southeast University, Nanjing, China, in 2009. In 1999, he joined the School of Mechanical and Electrical Engineering, Jiangxi University of Science and Technology as a lecturer. Currently, he is an Associate Professor in the department of Electrical Engineering and Automation. His major research interests include the analysis and design of permanent magnet synchronous machine, wind power technology.

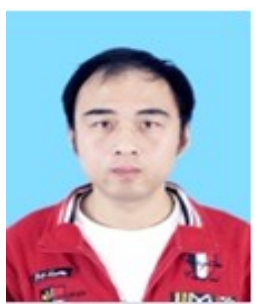

Chen Wang received the B.S. degree from Xidian University, Xi'an, China, in 2010 . He is currently a postgraduate student in the department of Electrical Engineering and Automation, Jiangxi University of Science and Technology. His major research interests include the design and analysis of permanent magnet synchronous machine.

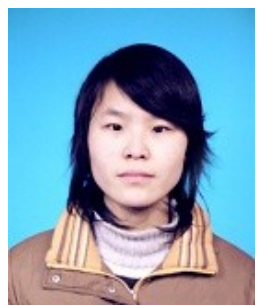

Aihua Zheng received the B.S. degree from Pingdingshan University, Pingdingshan, China, in 2010. She is currently a postgraduate student in the department of Electrical Engineering and Automation, Jiangxi University of Science and Technology. Her major research interests include the design and analysis of permanent magnet synchronous machine. 